\title{
Teaching for Epistemological Difference: Decentring Norms in Environmental Studies
}

\author{
M.J. Barrett \\ University of Saskatchewan
}

Many environmental educators and philosophers have identified anthropocentrism and the socially constructed separation between humans and "the more-than-human world" (Abram, 1996) as primary root causes of current ecological devastation. This separation is embedded in Western schooling content and structures and is often unintentionally reinscribed by educational content and practices. This paper describes three ways I work to disrupt this artificial separation between humans and the non-human 'nature' within a graduate level course: 1) attention to discourses; 2) offering counternarratives; and 3) provision of experiences that support ways of knowing and being introduced in course readings and class lectures.

\section{Introduction}

$\mathrm{M}$ any environmental educators (e.g., Barrett, 2009; Bell \& Russell, 2000) and philosophers (e.g., Abram, 2010; Plumwood, 2002) have identified anthropocentrism and the socially constructed separation between humans and "the more-thanhuman world" (Abram, 1996) as primary root causes of current ecological devastation. This separation is embedded in Western schooling content and structures (Gruenewauld \& Smith, 2008) and is often unintentionally reinscribed by educational content and practices. This paper describes three ways I work to disrupt this artificial separation between humans and the non-human 'nature' within a graduate level course: 1) attention to discourses; 2) offering counternarratives; and 3) provision of experiences that support ways of knowing and being introduced in course readings and class lectures. Given this context, and the fact that the course is situated in Plains Cree territory, exploration of animist perspectives were selected as central to the course.

The course, entitled ENVS 811: Multiple Ways of Knowing in Environmental Decision-Making, is set in the context of an interdisciplinary graduate program in environment and sustainability at the University of Saskatchewan. It involves critical examination of human-nature relations with particular emphasis on epistemology. Students 
are asked to analyze their own decision-making beliefs and practices in the context of multiple understandings of the world. Course objectives include: Understanding that there are multiple ways of knowing, all which are valuable to environmental decision-making, and that the higher status given to some knowledge systems over others has had significant (often negative) social, economic, and environmental effects. Students also become familiar with a range of explanations for animist and transrational knowing and appreciate the significance of engaging these in environmental decision-making from the perspective of making quality ethical decisions. They are also encouraged to practice integrating multiple ways of knowing into decision-making in both personal and professional contexts, as applicable.

\section{Theory}

Much of the course content supports creating spaces for a range of perspective on knowledge-making and decision-making processes. This includes both rational and transrational ways of knowing. By transrational, I mean those ways of knowing that are not against or counter to, but extend beyond Western rationality (Astin, 2004). These include unexplainable intuitions, gut feelings, sudden inspirations, embodied knowledge, dreams, nonverbal telepathic conversations with animals, and knowledge received through the use of a dowsing instrument.. Many of these ways of knowing have been central to ancient cultures around the world and are currently being brought forward in research methodologies such as dialogic inquiry (Barrett, 2011), intuitive inquiry (e.g., Anderson \& Braud, 2011), contemplative inquiry (Zajonc, 2008), some arts-based research approaches (e.g., Lipsett, 2002), and Indigenous methodologies (e.g., Debassige, 2010; Wilson, 2008). Unfortunately, these ancient ways of knowing have been both marginalized and silenced by the cognitive imperialism of Eurocentric traditions upon which Western academia was built and is frequently maintained (Battiste \& Henderson, 2000).
In the context of the limited epistemological frameworks given acknowledgement in many academic contexts, support is needed for expressions of knowing that transcends rational empirical methods of knowledge production. This minimally requires 'trans-systemic' methods and processes (Battiste 2007) that reach beyond normative (in academic contexts at least) systems of knowledge and support deepened understandings of Indigenous ways of knowing. Although multiple epistemologies are engaged, I will focus on animism for this particular paper since it forms a significant amount of the course content. While scepticism is important to engage in the face of all knowledge claims, it is equally important that particular ways of knowing should not be privileged over another, and criteria for assessment match the type of knowledge being assessed. Curriculum and pedagogical practices which decentre dominant discourses about the nature of knowing (epistemology) and reality (ontology) are necessary beginnings to realizing alternate ways of knowing, being, and learning.

Animism is a relational ontology that assumes the human-nature relations go beyond the physicalmaterial. In doing so, it challenges many aspects of the socially sedimented human-nature binary and hierarchy, and extends beyond conventional (within most Eurocentric academic contexts) epistemologies and ontologies. An animist ontology assumes nonhuman Others, or persons, such as trees, birds, rocks, clouds, rivers, and other entities not only possess selfconsciousness and intentionality (i.e., agency), but are able to "communicate intelligently and deliberately" (Harvey, 2006a, p. 187). Although animism is most often discussed in the context of Indigenous cultures, experiences of animism exist in diverse cultural contexts (e.g., Stuckey, 2010). As Harvey (2006a) notes, there are some cultures which are animist and others where one can be an animist even though the culture itself is not an animist one (see Barrett, 2009). These understandings of animism challenge previous definitions established within Eurocentric anthropological traditions, which associated animism with primitive cultures, superstition and immature spiritualism (Bird-David, 1999). The word 'spirit' is often not included in academic discussions of 
animism as it is currently being taken up by scholars such as Harvey (2006b), yet it lurks under the surface.

\section{Research and Praxis}

In the first of two post-course focus groups, students highlighted several key course components as foundational to their learning. Three of the most important are discussed here. They are: 1) attention to discourses and the multiple ways in which discourses enable and constrain what is thinkable and unthinkable (Britzman, 1995); 2) exposure to counternarratives through course texts, guest speakers, and class discussion; and 3) provision of experiences that support ways of knowing and being that were introduced in course readings and class lectures. I will spend most time on the first approach, then briefly introduce the second and third. Data collection and analysis is ongoing.

\section{Attention to discourses}

To help students understand discourses and their relative power they hold, I often work with a set of balance scales. I define discourses as sets of meanings (Weedon, 2004), or mini- and meta-narratives which take on the illusion of truth. These become entrenched, and are inscribed in bodies through everyday speaking and acting (Foucault, 1977/1995; Weedon, 2004), as well as through physical spaces (Probyn, 2003). As students are exposed to new understandings, attention to discourses which reinscribe their previous and well-entrenched understandings becomes essential, particularly as they discuss their new learning with other students, peers, or family members who in some cases, hold radically different perspectives. Discourses are the actions (or the verb) of invisible assumptions; they reinscribe these assumptions with each speaking and acting. Making the work of discourses visible is often an important first step in reducing the power they have to invisibly prescribe what is often assumed to be normal, unchangeable, and real.

As a class, we identify discourses prevalent within the course and students' personal and academic lives, then in some instances, use a balance scale to metaphorically demonstrate that discourses hold power (weight), that power produces subjectivities (who one can be), and affects individual agency, (a person's ability to act and think independently). For example, discourses of animism have relatively little weight if spoken in isolation and would generally be represented by a kernel of popcorn on the scale. But in the context of increasing recognition of the limitations of one perspective or worldview, raising frustration with the lack of successful resolution of complex environmental dilemmas using current approaches, and increased acknowledgement of the value of Indigenous knowledges, discourses supportive of animist sensibilities are finding increased traction. Consequently, in some contexts, they may have more power (perhaps the weight of a large marble). In others,particularly those that are entrenched in the metanarratives of material realism, they are still easily dismissed. To help students get better at identifying discourses and the ways in which they are at work in their lives, I introduce the discourse game. Throughout the rest of the course, I ask students, both in their day-to-day interactions, and within the course itself, to identify "big D" discourses (Rogers, 2004) that, as educational scholar Kumashiro (2004) notes, make some things possible or do-able, and others impossible. What are the epistemological discourses that make it impossible to use dreams as data, or to inform important decisions? What ontological discourses make experiences of telepathic communication with animals seem impossible to imagine as anything more than metaphor (see Nadasdy, 2007; Sheldrake \& Smart, 2000)? What discourses are at work, where do they originate, and upon what underlying understandings of reality are they based? And what are the perceived or actual risks when these discourses are challenged or, conversely, what might they enable if such counternarratives are engaged? All of these questions feed back into our discussions of what ways of knowing are able to be used in environmental management decision-making processes. They also clarify the relative safety of explicitly engaging them in their personal, academic and professional contexts.

\section{Introduction of counternarratives}

Through course texts, guest speakers, student presentations, and class discussions, students are intro- 
duced to a variety of counternarratives which challenge dominant and prevailing discourses within the fields of environmental sciences and resource management. In addition to guests from outside the university, student presentations also provide significant opportunities for expressions of diverse epistemological perspectives. Hearing diverse points of view from peers and invited experts enhances course readings by providing live and often storied representations of diversity. In introducing these different perspectives, I emphasize that the point is not to advocate for replacing one knowledge system with another, but rather to create a shared ethical space (see Ermine, Sinclair, \& Jeffrey, 2004) where individuals can begin to imagine how multiple ways of knowing - including transrational and Indigenous knowledges - can be used to address complex environmental problems.

\section{Direct experience}

Students are given numerous opportunities to attend to their own multiple ways of knowing through course assignments and in-class activities. To counter the emphasis on intellectual knowing present in most academic settings, I introduce a series of in-class activities to help students become more comfortable accessing ways of knowing that transcend rationality. These activities lead up to the Natural History Journal assignment which invites students into a practice of what Conn (2007) talks about as a restored ecological consciousness. It requires that students slow down and pay attention to direct perceptual knowing based on direct experience with a non-human being. The first step is to allow themselves "to be chosen by a natural being" (Conn, 2007), then to spend 20 minutes or more with that being at least two times a week. Students keep a journal of observations, insights and experiences and reflect on these through a synthesis assignment at the end of the course. In all three of the offerings of the course, many students have identified this assignment as critical to their understanding of the counternarratives presented.

\section{Summary}

Based on student feedback in post-course focus group, meeting course learning objectives requires a suite of pedagogical approaches. For these students, three strategies were identified as essential: exposure to counternarratives, identification of constraining discourses, and direct experience. A learning atmosphere conducive to exploration of new, and often challenging ideas, as well as time to process what they were learning were also viewed to be essential.

\section{Acknowledgements}

I would like to acknowledge the support of the Social Sciences Research Council of Canada and the University of Saskatchewan Teaching Learning Scholar grant for financial support, the students who participated in the focus groups and surveys, and Dr. Sheryl Mills, Gwenna Moss Centre for Teaching Effectiveness, for assistance with design and facilitation of the focus groups.

\section{References}

Abram, D. (1996). The spell of the sensuous: Perception and language in a more-than-human world. New York: Vintage Books.

Abram, D. (2010). Becoming animal: An earthly cosmology. New York: Pantheon Books.

Anderson, R. \& Braud, W. (2011). Transforming self and others through research: Transpersonal research methods and skills for the buman sciences and humanities. New York: SUNY.

Astin, A. (2004). Why spirituality deserves a place in liberal education. Liberal Education, 90(2), 34-41.

Barrett, M.J. (2009). Beyond human-nature-spirit boundaries: Researching with animate EARTH. Unpublished doctoral dissertation. University of Regina, Regina, SK.

Barrett, M.J. (2011). Doing animist research in 
academia: A methodological framework. Canadian Journal of Environmental Education, 16, 123-141.

Battiste, M. (2007). The struggle and renaissance of Indigenous knowledge in Eurocentric education. In M. Villegas, S. Rak Neugebauer, \& K.R. Venegas (Eds.), Indigenous knowledge and education: Sites of struggle, strength, and survivance (pp. 85-91). Cambridge, MA: Harvard Educational Publishing Group.

Battiste, M. \& Henderson, J. (2000). Protecting Indigenous knowledge and heritage: A global challenge. Saskatoon, SK: Purich.

Bell, A. \& Russell, C. (1999). Life ties: Disrupting anthropocentrism in language arts education. In J. Roberson (Ed.), Teaching for a tolerant world: Grades K- 6 essays and resources (pp. 68-89). Urbana, IL: National Council of Teachers of English.

Bird-David, N. (1999). "Animism" revisited: Personhood, environment, and relational epistemology. Current Anthropology, (40 Supplement), S67-S91.

Britzman, D. (1995). Is there a queer pedagogy? Or stop reading straight. Educational Theory, 45(2), 151-165.

Conn, S. (2007). Psychology in a new key: Ecopsychology and ecological consciousness. Keynote presentation at the PsychologyEcology-Sustainability Conference. Portland, OR: Lewis \& Clark College.

Debassige, B. (2010). Re-conceptualizing Anishinaabe Mino-Bimaadiziwin (the good life) as research methodology: A spiritcentered way in Anishinaabe research. Canadian Journal of Native Education, 33(1), 11-28.

Ermine, W., Sinclair, R., \& Jeffery, B. (2004). The ethics of research involving indigenous peoples. Saskatoon, SK: Indigenous Peoples' Health Research Centre.

Foucault, M. (1977/1995). Discipline and punish: The birth of a prison (A. Sheridan Trans.). New York: Vintage Books.

Harvey, G. (2006a). Animism: Respecting the living world. New York: Columbia University Press.

Harvey, G. (2006b). Animals, animists, and academics. Zygon, 41(1), 9-20.

Gruenewald, D. \& Smith, G. (Eds.). (2008). Placebased education in the global age. New York: Lawrence Erlbaum Associates.

Kumashiro, K. (2004). Against common sense: Teaching and learning toward social justice. New York: RoutledgeFalmer.

Lipsett, L. (2002). On speaking terms again: Transformation of the human-earth relationship through spontaneous painting. In E. O’Sullivan, A. Morrell, \& M.A. O'Connor (Eds.), Expanding the boundaries of transformative learning: Essays on theory and praxis (pp. 215-228). New York: Palgrave.

Nadasdy, P. (2007). The gift of the animal: The ontology of hunting and human-animal sociality. American Ethnologist, 34(1), 25-43.

Plumwood, V. (2002). Environmental culture: The ecologicalcrisis of reason. New York: Routledge.

Probyn, E. (2003). The spatial imperative of subjectivity. In M. Anderson, S. Domosh, N. Pile, \& N. Thrift (Eds.), Handbook of cultural geography (pp. 290-299). London: Sage.

Rogers, R. (2004). An introduction to critical discourse analysis in education. Mahwah, NJ: Lawrence Erlbaum Associates, Publishers. 
Stuckey, P. (2010). Being known by a birch tree: Animist refigurings of Western epistemology. Journal for the Study of Religion, Nature and Culture, 4(3), 182-205.

Sheldrake, R. \& Smart, P. (2000). A dog that seems to know when his owner is coming home: Videotaped experiments and observations. Journal of Scientific Exploration, 14, 233-255.

Weedon, C. (2004). Feminist practice and poststructuralist theory (2nd ed.). Oxford: Blackwell Publishing.

Wilson, S. (2008). Research is ceremony: Indigenous research methods. Halifax, NS: Fernwood Publishing.

Zajonc, A. (2008). Meditation as contemplative inquiry: When knowing becomes love. Great Barrington, MA: Lindisfarne Books.

\section{Biography}

M.J. Barrett holds a joint appointment in the School of Environment and Sustainability and the College of Education at the University of Saskatchewan. Her research addresses questions of how a deepened understanding of Indigenous and other transrational ways of knowing can enable environmental students, professionals, and researchers to more effectively and respectfully understand and engage multiple knowledge systems in environmental management contexts. It also queries into social constructs which act as barriers to developing and applying such understanding, and how to convey these concepts to students. 